\title{
Painel de neuroimagem
}

Luciana Pardini Chamié*, Fernando Alves Moreira**

Serviço de Radiologia do Hospital Alvorada, São Paulo, SP

\section{História clínica}

ES, 22 anos, sexo feminino, com história de cefaléia de início há quatro meses, refratária ao tratamento com analgésicos.

\section{Imagens}

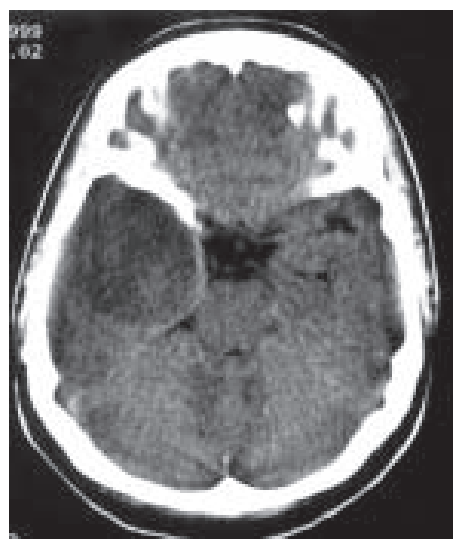

Figura 1 - Tomografia computadorizada sem contraste, corte axial, demonstrando área hipoatenuante ocupando a fossa temporal direita.

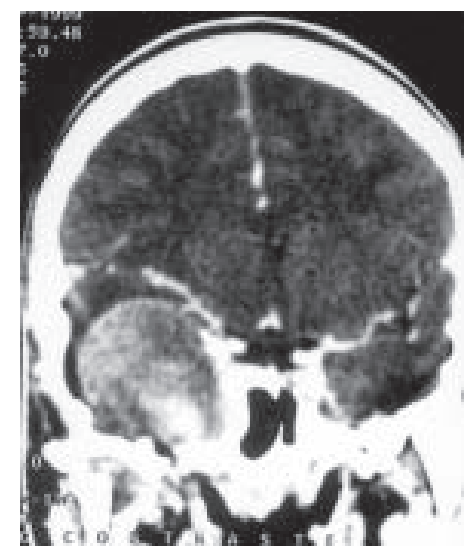

Figura 3 - Tomografia computadorizada com contraste, corte coronal, mostrando a situação parasselar da massa e desvio superior da artéria cerebral média direita.

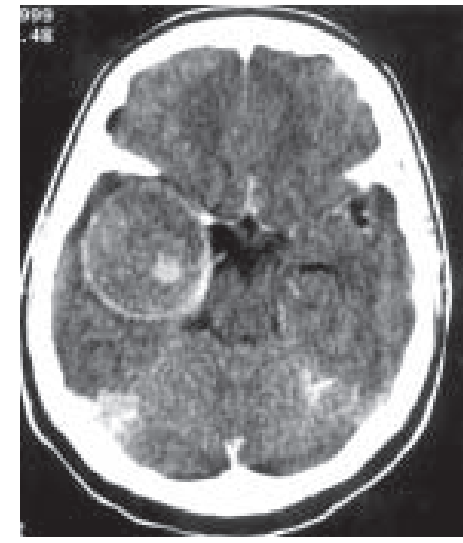

Figura 2 - Tomografia computadorizada com contraste, corte axial, demonstrando captação anelar e nodular central, observando-se aumento difuso da densidade da lesão.

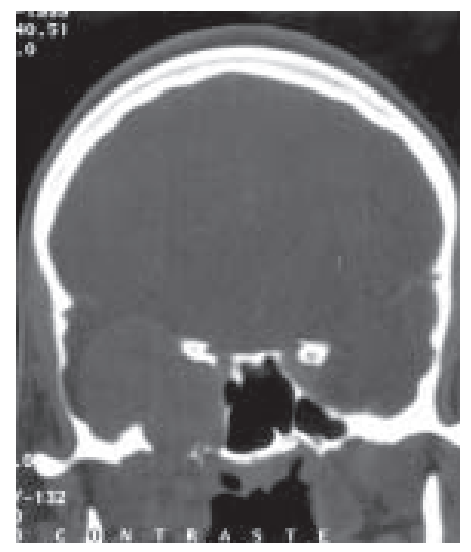

Figura 4 - Tomografia computadorizada em plano coronal, em janela para osso, demonstrando destruição do assoalho da fossa média e compressão da parede lateral direita do seio esfenoidal.

* Médica residente do Serviço de Radiologia do Hospital Alvorada.

** Médico chefe do Departamento de Diagnóstico por Imagem do Hospital Alvorada. 


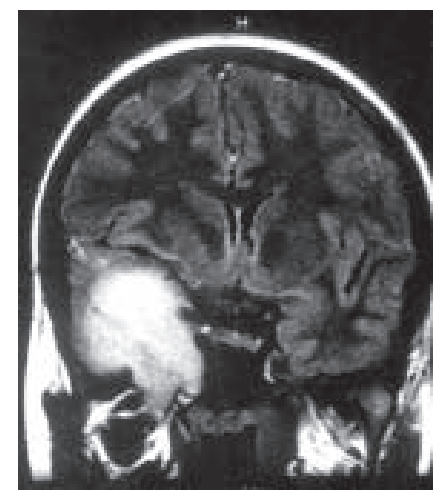

Figura 5 - Ressonância magnética com imagem enfatizando T1, após a injeção de substância paramagnética, em plano coronal, demonstrando a penetração da massa para a região mastigatória direita.
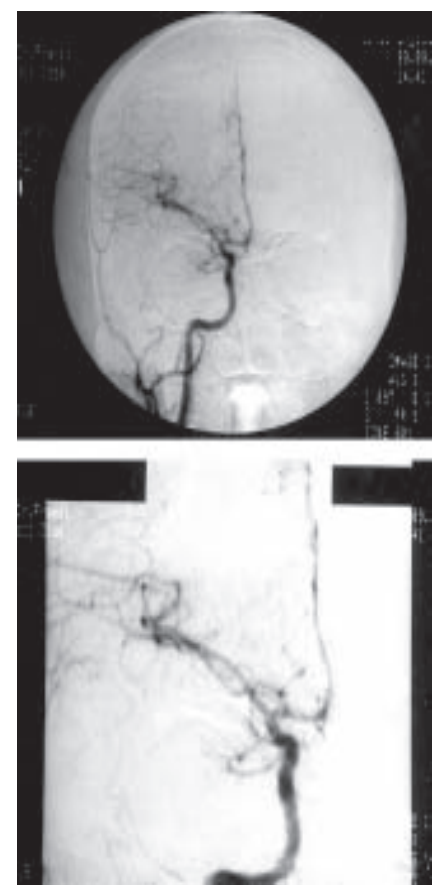

Figura 6 - Angiografia digital demonstrando massa hipovascularizada, nutrida por ramos durais, deslocando superiormente a artéria cerebral média direita.

\section{Diagnóstico}

Meningeoma fibroblástico.

\section{Discussão}

O meningeoma constitui o tumor de origem meníngea mais freqüente, representando $15 \%$ a $20 \%$ das neoplasias cerebrais primárias, acometendo principalmente mulheres entre 40 e 60 anos. Classificam-se segundo a Organização Mundial de Saúde em benigno típico ( $88 \%$ a 94\%), atípico (5\% a 7\%) e anaplásico (1\% a $2 \%)$.
O diagnóstico por imagem inclui métodos radiológicos convencionais e técnicas mais modernas, destacando-se a tomografia computadorizada (TC) e a ressonância magnética $(\mathrm{RM})$, que demonstram a imagem da lesão. A radiografia simples do crânio demonstra sinais indiretos como áreas de erosão óssea, hiperostose, alargamento dos canais vasculares, calcificação intratumoral e expansão para os seios paranasais. A angiografia demonstra que a grande maioria dos meningeomas são muito vascularizados, apresentando nutrição por vasos meníngeos, sendo os maiores nutridos também perifericamente por ramos piais gerando um aspecto típico em "radiações solares". As imagens em fase tardia demonstram contrastação vascular homogênea e prolongada.

A maioria dos meningiomas, na TC sem contraste, apresenta-se como uma massa arredondada ou levemente lobulada, bem circunscrita, em contato com a superfície dural, com a qual geralmente forma um ângulo obtuso, e é homogeneamente hiperdenso $(75 \%)$ em relação ao parênquima cerebral. Calcificações, difusas, ou focais estão presentes em $20 \%$ a $25 \%$ dos casos. Áreas císticas são incomuns ( $8 \%$ a $23 \%)$ e representam necrose e degeneração. Após a utilização de contraste endovenoso há realce intenso e relativamente uniforme $(90 \%)$ da lesão com edema periférico que pode ser extenso e envolver a substância branca de todo o hemisfério.

A aparência dos meningiomas em imagens de RM sem contraste é menos característica que a apresentada na TC. A intensidade de sinal do tumor em imagens ponderadas em T1 e T2 tende a aproximar-se do encéfalo normal, com iso ou hipointensidade de sinal em T1 e aspecto variável em T2, podendo ser heterogêneo devido à presença de alterações císticas, calcificações $\mathrm{e}$ vasos proeminentes. Como na TC, há rápida e intensa impregnação pelo contraste para-magnético na RM. Um afilamento de dura-máter realçada na margem do tumor (cauda dural) pode ser devido a disseminação ou reação da dural. Em geral a RM é superior à TC na determinação da localização extra-axial dessas lesões, do envolvimento de vasos e invasão de seios venosos.

Algumas vezes, os meningiomas podem simular outras lesões benignas como hematopoiese extramedular, angioma cavernoso, hemangiomas capilares e até aneurismas trombosados e calcificados, ou ainda lesões malignas como o astrocitoma anaplásico e tumores invasivos da base do crânio com suprimento vascular dural, sendo difícil sua diferenciação por um método isolado de imagem.

Original recebido em janeiro 2000

Aceito para publicação em março 2000

Endereço para correspondência:

Luciana Pardini Chamié

Rua Peixoto Gomide, 613, $2^{\circ}$ andar

CEP 01409-001 - São Paulo, SP 